Arqueología y Sociedad,

№ 22, 2010

\title{
LAS EXPOSICIONES DE ARTE EN LIMA DE PRINCIPIOS DEL SIGLO XX (1919-1924) EN LA CRÍTICA DE ARTE DE Carlos Solari SÁNCHez CONCHA PUblicAdA EN EL DIARIO EL COMERCIO DE LIMA
}

Karla Robalino Sánchez*

\section{Resumen}

La presente investigación tiene como finalidad rescatar y reconocer parte del desarrollo artístico de principios del siglo XX (1919-1924) del medio local limeño que evidencia la influencia del estilo moderno en la construcción del arte peruano.

Carlos Solari fue un crítico de arte peruano que trabajó en el diario El Comercio, comentando las exposiciones de arte realizadas entre 1919-1924. Durante estos años, la mayoría de autores utilizaban seudónimos para escribir. Solari, se hacía conocer como Don Quijote, también publicó en otros medios de prensa escrita, como Mundial aunque nuestra investigación se circunscribe al diario El Comercio.

Se ha considerado mencionar 3 exposiciones de pintura de los 14 pintores que refiere Solari en su crítica de arte.

\section{Palabras clave}

Crítica de arte, modernismo, simbolismo, introspección, elite.

\begin{abstract}
The art exhibitions in Lima at the early twentieth century (1919-1924), in the art critic of Carlos Solari Sánchez Concha published in El Comercio daily from Lima, Peru.

This research aims for rescuing and acknowledging a part of the artistic development of the early twentieth century (1919-1924) from the Lima local environment that shows the modern art influence in the Peruvian art construction.

Carlos Solari was a Peruvian art critic who worked in El Comercio newspaper, he commented on the art exhibitions carried out among 1919-1924. During these years, most authors used pseudonyms for writing. Solari became known as Don Quijote, also published in other print media as Mundial, although our research is limited to El Comercio daily.

It has been considered to mention three painting exhibitions of the 14 painters that Solari referred in his art criticism.
\end{abstract}

\section{Keywords}

Art critic, modernism, symbolism, introspection, elite.

\footnotetext{
* Licenciada en Arte. Facultad de Letras y Ciencias Humanas, Universidad Nacional Mayor de San Marcos. Museo de Arte de la Universidad Nacional Mayor de San Marcos.

Correo electrónico: krobalinos@gmail.com
} 
A Carlos por su apoyo incondicional.

\section{LAS EXPOSICIONES DE ARTE EN LIMA DE PRINCI- PIOS DEL S. XX (1919-1924) SEGÚN LA MIRADA Del CRítico de arte Carlos Solari Sánchez Concha PUblicAda EN El Diario El Comercio DE LIMA.}

Para analizar una crítica de arte se debe tener en cuenta que existen dos niveles condicionantes; el primero es el concerniente al proceso de creación, desarrollo y término de la obra a cargo del artista; el segundo que es observar, analizar y calificarla bajo consideraciones temporales, preferencias estilísticas y bagaje cultural del crítico.

Ésta investigación implica la crítica de arte, limitándonos a considerar el trabajo realizado por Carlos Solari en la posición de crítico de arte. Los juicios emitidos por Solari se dan en una línea de tiempo, y su ejercicio tiende al sentido del movimiento conocido como Modernismo ${ }^{1}$.

Es importante considerar el aporte cultural que en el lineamiento del modernismo "atrazado" del medio local limeño, ejerció Carlos Solari.

La emisión de un juicio crítico está circunscrita a la temporalidad, es decir que es vigente en el tiempo en que se realiza. Es sumamente importante para la investigación esta premisa, ya que bajo estos criterios los juicios críticos de Solari forman parte de la historia y el desarrollo artístico en el medio local limeño.

\section{Antecedentes peruanos a la crítica de aRTE DE CARlos Solari}

Como antecedente a la crítica de Carlos Solari, tenemos la labor desarrollada por Teófilo Casti-

1 El Modernismo o Art Nouveau se desarrolló hacia principios del siglo XX en su fase temprana en Inglaterra. Es de origen netamente europeo, incluso tuvo diferentes denominaciones "la alemana o Jugendstil, la austríaca o Sezessionstil, la catalana o estilo modernista (...) la parisiense de los años noventa, que muestra influencias de su modelo inglés, el llamado modern style, todas poseen peso y valor propios (...)"Schmutzler, 1985: 9; “...fue la fascinación por el movimiento que había alcanzado a todos los aspectos de la vida." Sembach, 2007:8 llo (1857-1922), que hizo una doble actividad, en el sentido que estaba en ambos espacios; nos referimos a la posición como artista y como crítico de arte. El trabajo efectuado por Castillo en el ámbito de la crítica, también dejó información de primera mano en lo referente a los sucesos y acontecimientos del medio limeño. Como ejemplo, la referencia a la creación de una Escuela de Bellas Artes y el trabajo crítico que hiciera con motivo de exposiciones realizadas en Lima.

Como contemporáneo a los escritos considerados en esta investigación, está el trabajo que realizó José Carlos Mariátegui (1894 - 1930) cuando escribía sus crónicas con el seudónimo de Juan Croniqueur (1914 - 1919). Esta primera etapa, que corresponde a su juventud, marcó su postura "sin los parámetros que de la imagen de José Carlos Mariátegui convicto y confeso podamos tener" ${ }^{2}$. Es necesario mencionarlo ya que Juan Croniqueur en sus publicaciones correspondientes a los años antes mencionados sigue el lineamiento Modernista referente a lo social, literario y urbano, que Carlos Solari también sustentó en el diario El Comercio.

Visto por José Carlos Mariátegui, el modernismo europeo también se vió representado en las actitudes sociales que las mujeres limeñas de principios de siglo empezaron a optar:

"Casi no existe ya, en la sociedad limeña, el cerrado conservadurismo de que se le ha acusado. El modernismo de las europeas, ha florecido poéticamente en nuestro medio. La deliciosa religiosidad de nuestras mujeres se ha hermanado con las páginas características de ese modernismo triunfante." ${ }^{3}$

Referíase Mariátegui al modernismo europeo y a las formas como la mujer limeña empezaba a preocuparse por el aspecto físico y de la imagen ${ }^{4}$.

Y otro punto importante que considera Mariátegui (Juan Croniqueur) interpretado por $\mathrm{Ri}$ cardo Portocarrero es que “(...) la hípica no sólo

2 Portocarrero, 1999: 373- 393

3 Ibid.: 379

4 Ibid. 
es un espectáculo aristocrático sino también es expresión de lo moderno (...)" ${ }^{\prime 5}$ y como parte del proceso de modernización urbana, tuvo mucha influencia por ello la construcción del Hipódromo de Santa Beatriz, considerando también la “(...) introducción de modas deportivas como el boxeo, el football, el tennis, la carrera de autos y la acrobacia aérea (...)" ${ }^{\prime 6}$. Como podemos observar el Hipódromo se convierte en esa época en un lugar de reuniones y encuentros de la gente elitista, además de ser el lugar de concentración y expectación de los medios.

Vemos que para esta época la apariencia es considerada muy importante, los espectadores burgueses que asistían a dichos eventos eran personas refinadas convirtiendo al hipódromo en un "espacio privilegiado para la moda, el flirt y la exhibición pública"7.

Con estas consideraciones queremos demostrar que el tema del Modernismo limeño no estuvo ajeno en la sociedad elitista; aunque no haya tenido los resultados que se esperaban, la influencia de los periodistas y escritores que ejercían a través de sus columnas escritas en los diarios fue fuerte, entre ellos Emilio Gutiérrez de Quintanilla y Abraham Valdelomar. Con esto también demostramos que el trabajo crítico de Carlos Solari no fue un caso aislado, sino más bien una continuación del lineamiento modernista en el ambiente artístico cultural limeño.

\section{Referentes biográficos de Carlos Solari SÁnchez Concha (Lima, 1883 - New York, 1932)}

El crítico de arte $^{8}$ nació en Lima en 1883, hijo de Luis Fernando Solari y Argumaniz y de Juana Sánchez Concha y Guzmán. Su niñez se desarrolló entre Europa y España. Realizó sus primeros estudios en Inglaterra. Por su ascendencia y formación, tuvo arraigada influencia europea.

De regreso al Perú continuó su aprendizaje
5 Ibid.: 380
6 Ibid.: 381
7 Ibid.
8 Paz-Soldán, 1921: 448

en el colegio La Recoleta y en el de los Jesuitas. Ingresó a la Universidad de San Marcos para seguir estudios en la facultad de Letras y Jurisprudencia. Por motivos de salud, tuvo que abandonarlos para trasladarse a Jauja y recuperarse.

El 26 de diciembre de 1909 se casó con María Virginia Isabel Valentina Swayne y Mendoza. Asistió a la ceremonia Augusto B. Leguía quien se convertiría en su tío político y futuro presidente del Perú9.

Años más tarde Solari se desempeñó como el primer Introductor de Embajadores del Ministerio de Relaciones Exteriores del Perú, razón por la cual formó parte de la comitiva del cuerpo diplomático ${ }^{10}$. En 1919 fue nombrado intérprete del Ministerio de Relaciones Exteriores ${ }^{11}$.

En su matrimonio tuvo seis hijos, destacándose “(...) Manuel Solari Swayne, cronista de toros y defensor del patrimonio cultural limeño, y don Enrique Solari Swayne, autor de las piezas teatrales Collacocha, y La mazorca, y de la novela Juanito de Huelva (...)"12

Carlos Solari Sánchez Concha fallece el 26 de abril de 1932, en la ciudad de New York ${ }^{13}$ "Apasionado del arte, hizo crítica de música y pintura (...), con el seudónimo de Don Quijote, que logró popularizar, destacándose como un Conaisseur ${ }^{14}$ de fino temperamento artístico. Fue miembro de la redacción de El Comercio"15.

\section{La crítica de Carlos Solari Sánchez CONCHA Y SU IMPORTANCIA (1919-1924)}

En el Perú los principales diarios La Prensa, El Comercio, las revistas Variedades y Mundial estuvieron vigentes en el medio local limeño. El Comercio, uno de los medios de comunicación más influyentes, no cubría en su totalidad las ac-

\footnotetext{
9 Swayne, 1940:17

10 El Comercio, 1994: 35

11 Paz-Soldán, 1921: 448

12 Sánchez, 1999: 237-290

13 Anónimo, 1932: 12

14 Traducido al español como conocedor o experto

15 Swayne, 1940: 17. También en Sánchez, 1999: 237290
} 
tividades en lo que se refiere a las exposiciones artísticas.

Aunque pocos, se publicaron artículos concernientes a las exposiciones de pintura, dibujo, etc., en El Comercio los que, además de ser en su mayoría anónimos ${ }^{16}$, indicaban lo indispensable.

Uno de los puntos a resaltar son los espacios o lugares donde se exhibían las obras, no exclusivos para este fin, sino que eran compartidos con la venta de productos importados de diferentes tipos y calidades (locería, muebles, prendas de vestir, etc.), negocio principal y fuente de ingresos de la casa comercial ${ }^{17}$, la cual mantenía sus vínculos con el público elitista de la época.

Cuando los artículos sobre exposiciones de pintura comenzaron a ser publicados en el diario El Comercio, invadiendo sus columnas, los autores se limitaban a describir las obras sin imágenes que pudieran recrear al lector, contrario a lo que hacían las revistas Variedades y Mundial. Es probable que la carencia de fotografía se deba a una política editorial del periódico que no se limitaba en las imágenes relativas a Europa. Esta forma continuó vigente en la primera mitad de la década del veinte.

Los críticos de arte de otros medios de difusión escribían con emotividad y hasta se diría poéticamente al describir una obra realizada en Perú, considerándosele como efectivista ${ }^{18}$. Su entusiasmo al compararlas con las grandes obras occidentales era exagerado, y mostraban preferencias subjetivas.

Las personas encargadas de la redacción en el diario se identificaban con seudónimos, muchos conocidos por los investigadores de hoy ${ }^{19}$.

16 Como ejemplo tenemos el anuncio de las exposiciones de los artistas Morey, Quízpez Asín y Emilio Goyburu. (Anónimo, 1920b: 3)

17 Tenemos el ejemplo de la Casa Welsch, una de las casas comerciales reconocida por comercializar productos traídos desde Europa; y entre estos incluían pinturas de artistas europeos para su exposición-venta. (Anónimo, 1920a: 1)

18 Nos referimos a la forma literaria de describir un trabajo, obra, crítica.

19 Por ejemplo tenemos el seudónimo de Juan de Ega
Carlos Solari no fue ajeno a esta práctica ${ }^{20}$.

Al final, y en la parte inferior de los artículos firmó como Don Quijote, personaje principal de la obra de Miguel de Cervantes Saavedra (era común en la época firmar con sobrenombres). Carlos Solari firmaba con el seudónimo completo con el cual la mayoría de la gente vinculada e interesada en el mundo artístico de la época lo reconocía; algunas veces sólo lo hacía con las iniciales D.Q. ${ }^{21}$

Solari escribía en la sección denominada Notas de Arte. Esta columna no sólo incluía las exposiciones o algún acontecimiento que involucrara a pintores, sino que también en ella se publicaban artículos sobre música.

Carlos Solari Sánchez a los 26 años, incursiona por primera vez en el mundo crítico-artístico y periodístico en el mes de junio de 1919, en la citada columna dedicada a difundir los acontecimientos artísticos culturales: Notas de arte, con un artículo referido a la muestra de caricaturas de Pedro Challe, José Alcántara Latorre y Víctor Morey ${ }^{22}$.

Si bien Solari no tuvo una educación estrictamente estética o crítica, tuvo una proveniente de las humanidades propia de la época, que le valió para realizar sus artículos.

Entre 1919 y 1924 escribió un total de 29 artículos. En ellos abarca temas sobre pintura, caricatura, acuarela, dibujo, escultura, arquitectura y algunas consideraciones educativas, siendo la pintura el más desarrollado. También señalamos que los artículos publicados no fueron continuos; el mayor tiempo que no publicó artículos llegó hasta once meses, tal vez fue por cuestiones de trabajo ya que ocupó el cargo de jefe de redacción en el diario El Comercio.

Nuestro aporte para esta publicación es lo concerniente a las exposiciones de pintura reali-

cuyo verdadero nombre era José Chioino. Esto se puede comprobar en el artículo publicado por él "Visitando la exposición José Sabogal”. (Chioino, 1921: 5 )

$20 \mathrm{Se}$ afirma su identidad en su artículo (Solari, 1921: 2)

21 Tenemos ejemplos en: 1921a: 2; 1921b: 4 y 1923: 3

22 Don Quijote, 1919: 2 
zadas a principios del siglo XX en el medio limeño bajo la mirada crítica de Carlos Solari Sánchez Concha, que a continuación desarrollaremos.

\subsection{Las exposiciones de pintura}

De los veinte artículos referentes solo a pintura, Solari maneja un abanico de referencias tanto locales como extranjeras.

Debemos tener en cuenta también que algunas exposiciones se llevaron a cabo en torno a fechas relevantes como son los casos del Centenario de la Independencia del Perú y el Centenario de la Batalla de Ayacucho.

Hemos considerado conveniente mencionar sólo a tres de los catorce pintores que desarrolla Carlos Solari, que para la época se encuentran vigentes en Lima.

\subsubsection{Jorge Vinatea Reinoso (Arequipa, 1900. 1931)}

Solari habla sobre la exposición que hiciera Vinatea Reinoso en la Fotografía Rembrant. En ella se pudo apreciar caricaturas y algunas acuarelas (Figura 1 referencial). Solari sólo dice: "algunas acuarelas interpretativas de paisajes, muy sinceras por cierto, y además luminosas y animadas (...)"23, sin comentar nada más sobre ellas. De esto deducimos su preferencia por los paisajes y el trabajo que observa en la interpretación subjetiva dada por el artista; además reconoce el trabajo de la luz que se impone en estas obras.

Sobre las caricaturas dice Solari:

"La técnica de Vinatea es infantil, pero Vinatea hace reir. Esto es un elogio muy grande y muy merecido. Vinatea es un intuitivo del dibujo y su intuición es tan grande que él, que no aprendió á dibujar, ya que sabe hacer y con intenciones psicológicas muy definidas, dibujos muy cómicos de los que todos ríen a bon couer...... He dicho que Vinatea dibuja intuitivamente con comicidad que maravilla. Entre las muchas caricaturas

23 Don Quijote, 1920a: 4 del Dr. M.. I.. P.. y U.. y del doctor L.. M.. Q..? ¿No? Pues mírenlas y digan si se puede sorprender mejor determina [no es legible] y salpicar con una más malvada benevolencia un poco del barro de que somos hechos todos (...) Si Vinatea sigue estudiando como ahora lo hace, y continúa en esa su simpatiquísima modestia, Vinatea irá muy lejos. Quiera Dios que así sea." ${ }^{24}$

Solari reconoce en Vinatea Reinoso un intuitivo del dibujo; maneja bien la técnica; basada en el estudio psicológico del representado, puede sacar y sintetizar a través de líneas las diferentes expresiones y características de un personaje. La intención de una caricatura es hacer reír a través de los defectos exagerados y encontrados en determinada persona. Vinatea logró ese objetivo e hizo reír al público asistente. Reconoció además cierta modestia que a él le llamó la atención, pues rompía ese hito que los artistas son dioses y dueños de toda verdad y de creerse originales en sus obras:

"Vinatea es muy modesto. No se cree genio. Parece que ignorara que tiene un gran talento. Apunto este rasgo por raro entre nosotros. ¿Quién que aquí presenta ante el público no es genio incontrovertible? ¿Quién que borronea unas cuartillas no se cree Francisco García Calderón? ¿Quién que embadurna un lienzo no piensa ya en tener á menos á Daniel Hernández ó á Teófilo Castillo? La modestia de Vinatea es pues un signo de que él de la vulgaridad se aparta y esto sólo ya indica que Vinatea está muy por encima de la vulgaridad (...)"25

Como segundo artículo la referencia que hace Solari es sobre Jorge Vinatea junto a Elena Izcue. Solari sólo los comenta incluídos en el artículo escrito a propósito de la visita que se hiciera a la Escuela de Bellas Artes. Aunque no menciona características ni lineamientos de ellos, ambos participarían junto a Daniel Hernández y José Sabogal en la muestra y decorado del salón de recepciones del Palacio de Gobierno. "También Vinatea Reinoso y la señorita Iz-

24 Ibid.

$25 \mathrm{Ibid}$. 
cue contribuyen con brillante éxito a la decoración normal (...)"26

Deja de ésta manera escrito la participación de estos pintores en las celebraciones del Centenario de la Batalla de Ayacucho.

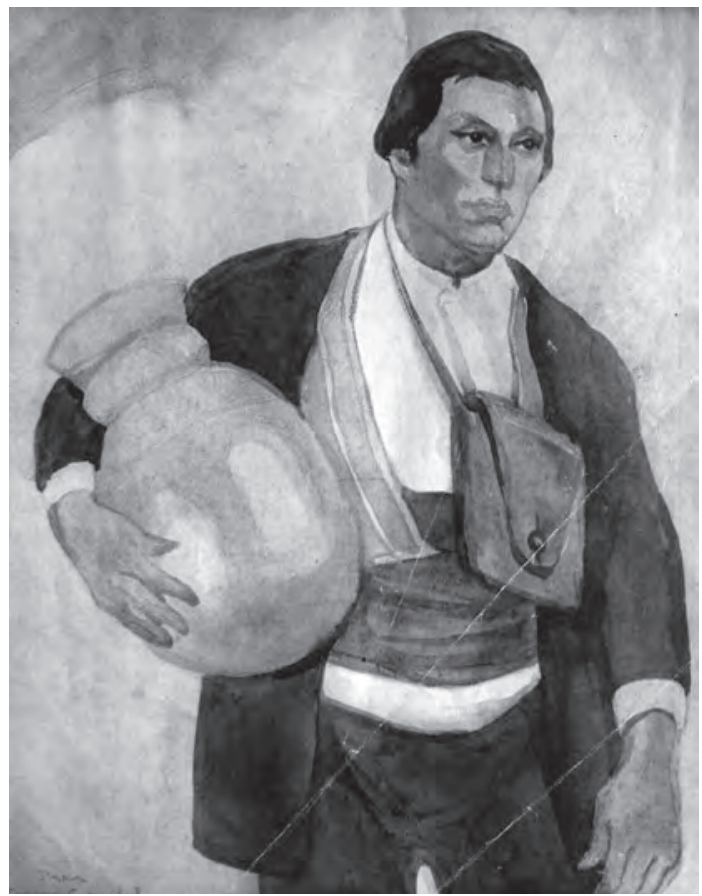

Figura 1. Vinatea Reinoso, El indio del cántaro, acuarela. En Revista Mundial, 1923. Carátula.

\subsubsection{Stephen Koek Koek (Londres, 1887 - Chile, 1934)}

En el caso de este artista, Carlos Solari escribe tres artículos sobre sus exposiciones, como parte de las que dedica a artistas extranjeros en Lima. El inglés Stephen Koek Koek llegó desde Buenos Aires luego de haber realizado dos muestras; traía como referencia la carta del escritor uruguayo Juan José de Soiza Reilly ${ }^{27}$.

Solari como observador y crítico, considerando la referencia dada por Soiza Reilly, co-

26 Don Quijote, 1924:2

27 "Cronista admirable, el reportero sud-americano más audaz y una de las figuras literarias más singulares y rotundas del continente" (Jufebrand, 1920: 3) mentó sobre la muestra del inglés lo siguiente:

“(...) puede decirse que Koek Koek es también un gran poeta del color (...) A través de una técnica hecha á base de un sabio y moderno sintetismo, Koek Koek es un fervoroso cultivador del "prerafaelismo" inglés ${ }^{28}$, aquel que exaltara Ruskin y que tuvo en la gigantesca figura de Burne Jones su más original y noble expresión." ${ }^{29}$

Con estas líneas Solari muestra la asociación del artista con la forma pictórica modernista. Es fundamental resaltar que es la tendencia por la que juzga. Menciona aquí el "moderno sintetismo", considerado por él como la simplificación para representar a los personajes, animales o cosas, que se puede observar en las obras pictóricas. Esta forma de ver diferente las obras, ya no resaltando los detalles academicistas sino los simplificados, es válida como modernismo o moderno, innovación que trató Solari que se asimile en el medio artístico cultural de la época y que son características fundamentales del estilo.

“(...) con predilección, a las marinas donde su espíritu de ciudadano de la pequeña y formidable isla es una forma nueva de una gloriosa tradición de arte peculiar y nacionalista. Esos cuadros en los que los rojos soberbios tienen siempre la majestad de la púrpura deben quedar todos en Lima. Así lo exige la honrosa tradición artística de nuestra vieja ciudad." 30

Cabe resaltar otro punto, Solari reconoce en el artista la preferencia por las marinas, considera también que el trabajo que realiza es un arte nacionalista, porque representa las marinas con ciertas características inglesas, debido a su origen. De esta manera, publicitando a Koek, le

28 “(...)en reacción contra el academicismo dominante, Dante Gabriel Rossetti (1828-1882), William Colman Hunt (1827-1910) y Jhon Everett Millais (18281896) constituyeron la cofradía prerrafaelista, en 1848, inspirándose no sólo en los libros de Ruskin sino en las pinturas de Madox Brown y los grabados de Lasinio según las pinturas de Camposanto de Pisa (...)"(Venturi, 1949: 144)

29 Don Quijote, 1920b: 1

30 Ibid. 
da la bienvenida al pintor que estuvo de paso por nuestro país y que, al margen de ser extranjero, acaparó gran parte de las primeras páginas del diario El Comercio y, por ende, la atención del público y el de otros críticos de arte como Juan Pedro Paz Soldán, quien escribió:

"Este sí que es un artista excepcional que sabe arrancarle a la naturaleza sus más bellas manifestaciones y que tiene el don de reflejar en sus telas las combinaciones de luz más difíciles, produciendo obras de arte, ricas de colorido y animadas de vida real y palpitante. La impresión que se experimenta delante de cada uno de los cuadros de Koek-Koek es verdaderamente deliciosa. El artista tiene el talento de elegir temas nobles y de reproducir en forma maravillosa, rincones llenos de belleza y de irresistible atractivo." ${ }^{31}$

En este artículo Juan Pedro Paz Soldán recalca el valor de las representaciones de los paisajes de Koek Koek, caracterizadas por la amplia gama de colores que utiliza, el manejo de la luz y la justa elección del tema. Paz Soldán se lleva una grata impresión de la obra del inglés, especialmente en el caso de los paisajes.

El segundo artículo de Solari referido a Stephen Koek Koek, es sobre la acogida que le dieron los limeños y la venta de algunos de los cuadros (Figura 2), sugiriendo al público su adquisición:

“(...) abrió la exposición de la que se enteraron todos (...) pero Koek Koek ya se marchó y aún quedan algunos de esos cuadros que hoy saldrán a remate (...) Si acaso hubiera lectores que conceder pudieran alguna autoridad á un consejo mío, yo á tales lectores les diría: adquirid esos cuadros." ${ }^{32}$

También menciona Solari que las obras están cargadas de simbolismo, otra de las características de la tendencia modernista que Solari apoya en el medio limeño. “(...) en cada cuadro expone una faz de un misterio y traza en colores el signo de una interpretación." ${ }^{33}$ Para Solari el

$31 \mathrm{Paz}, 1920: 1$

32 Don Quijote, 1920c: 3

33 Ibid. significado de simbolismo es la expresión que le puede dar un artista a los temas en sus telas a través de los colores, una carga emotiva trabajada de una manera tal, que demuestra el dominio al combinar los colores y que también cautiva a los espectadores.

El tercero y último publicado después de un año (1921), en realidad está incluído en el artículo con motivo de la Exposición de Eguren Larrea. Este tuvo más párrafos dedicados a Koek. El motivo de escribirlo fue para defender al pintor, en respuesta por un escrito de Felipe Rotalde:

“(...) Koek Koek, en cuyos cuadros no se podía precisar la hora, pues que en muchos de ellos se veían velas de barcos, alumbradas por un sol mañanero, sobre un fondo que era un cielo del más puro crepúsculo. Disparate garrafal que pasó desapercibido." ${ }^{34}$

Solari, frente a esto responde:

"Aquí está en error Rotalde. Esa que él cree inadvertida de la crítica, es pura y sencillamente un lapsus de su propia retina (...) iconoce acaso Rotalde las regiones del norte de Europa?, y si no las conoce ¿Cómo se echa á dogmatizar sobre la falsedad colorista de las telas de Koek-Koek pintara en la región donde precisamente el sol, en sus raras apariencias, es como nunca misterioso y como nunca evocador y caprichoso? Nosotros tampoco conocemos la costa de Holanda ni el Mar del norte; pero si conocemos la labor de muchos artistas que de estas regiones se han ocupado, y podemos asegurar que esa misma falsedad que cree advertir Rotalde en algunos lienzos de Koek-Koek, se observan en los panoramas de brumas y luz sorprendidos por pintores eminentes." ${ }^{35}$

Las referencias de Solari a lo "misterioso" y "evocador" son calificaciones modernistas ya que al reinterpretar e interiorizar los temas, estos se reflejan a través de los colores.

Solari continúa con la defensa del artista, considerando que su obra tiene una fuerte carga

34 Don Quijote, 1921c: 2

35 Ibid. 


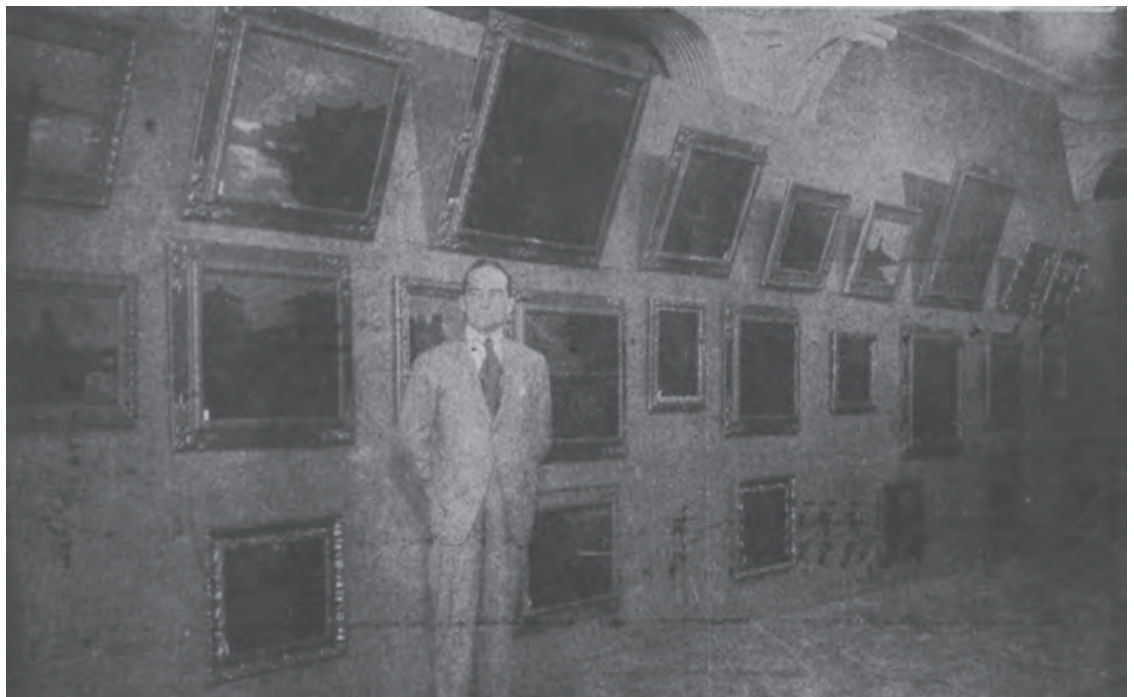

Figura 2: C.P. La exposición Koek-Koek. En Revista Variedades, 1920: 247.

de simbolismo y reinterpretación subjetiva, expresada a través de los colores. Igualmente, determina la tendencia y la fuerte influencia que las obras de los prerrafelistas ingleses hicieran en la obra de Koek-Koek:

"El sol que es desconcertante (...) es á la vez rojo y pálido como si quisiera presentar á los hombres ensueños fugaces de lujuria y de idealismo. Koek-Koek ha sido, de todos los pintores que entre nosotros se han presentado, el que encontró un ambiente menos preparado para juzgarlo. Koek-Koek es un fervoroso enamorado y cultivador del prerafaelismo inglés. Esta escuela - de la que no sabemos que en Lima haya un solo exponente- necesitó para imponerse en la misma Inglaterra, un tan formidable representante como Burne Jones, y ser apadrinada ardorosamente por un Ruskin." ${ }^{\text {36 }}$

Para Solari, los colores usados por KoekKoek son reinterpretaciones de momentos que interesaron al artista frente a lo que él, como crítico y observador, quedó cautivado.

Podemos deducir también, que Solari gusta mucho de la tendencia prerafaelista, por la forma en que describe, defiende y compara a Koek-Koek con las características de este movi-

36 Ibid. miento artístico, y también deducimos que ese gusto estaba influenciado, ya que gran parte de su infancia transcurrió en Inglaterra.

\subsubsection{José Sabogal (Cajabamba, 1888 - Lima, 1956)}

Debemos mencionar que antes de los artículos ahora tratados, hubo otra publicación de Solari referida a José Sabogal, la del 28 de julio de 1921; fue una polémica entre el crítico y el artista. $^{37}$

Son tres artículos escritos por Solari respecto a las exposiciones de pintura que hiciera José Sabogal en Lima.

El primero de ellos referido hacia 1919 realizada en la Casa Brandes es extenso; en él habla de Sabogal como debutante. "El pintor era un ilustre desconocido. Venía de Buenos Aires donde había despertado la curiosidad de los del mentier (...)" 38 . Solari comenta:

"(...) las telas que exhibió eran desconcertantes contradicciones. En algunos nocturnos llegaba Sabogal casi al misticismo implorante; en ciertos paisajes se convulsionaba el amor terruño, y en múltiples estudios

37 Robalino 2009:84.

38 Don Quijote 1921a: 1 
de figuras humanas era en el mismo cuadro soberbio de verismo, y dibujante desalineado; rico en color y agrio en la tonalidad; luminoso y sucio; admirable y feo" ${ }^{\prime 39}$.

La dura crítica señala que ninguno de los temas es acertado en el empleo y desarrollo de la técnica pictórica. Pero que, sin embargo, le dejó una gran curiosidad el catálogo que el propio Sabogal elaboró a mano para esa muestra. Para Solari este trabajo demostraba gran habilidad "(...) Y -dato curioso- el catálogo (...) era un trabajo á pluma de una estilización admirable y había sido hecho por el mismo Sabogal (...)" ${ }^{\text {40 }}$.

Comenta también que Teófilo Castillo vió en éstas, las primeras obras de Sabogal a un gran artista pero que le faltaba dar un gran paso. Como escribiera Solari, para Castillo:

"Es un gran pintor Sabogal; es un gran pintor, repetía Castillo; un gran pintor al que le falta dar un salto, que ya lo ha de dar y entonces verán ustedes. Quien dibuja así (Castillo blandía nuevamente el catálogo) y hace ya con el color todo lo que dicen esos cuadros, es gran pintor, es un gran pintor." ${ }^{\prime 1}$

En líneas posteriores Solari menciona la ausencia de algo en los cuadros de Sabogal en aquella primera exposición “(...) era evidente en ellos, nada habría de vulgar; que en ellos había un sello propio, un algo que perdura; pero era evidente también que en todas las telas faltaba algo, algo que al faltar las dejaba feas" ${ }^{\prime 2}$, y comenta:

"Lo que faltaba era el dominio del pintor sobre sí mismo al producirse, dominio que llegaría á ser equilibrio; equilibrio que sería elegancia (...) faltaba distribuir bien la fuerza de un gran motor. Así lo comprendió don Daniel Hernández, y puesto á la obra el gran maestro ha probado una vez más que gran maestro es efectivamente. Hernández cogió a Sabogal y se puso á labrar un diamante en bruto $(. .) "$.

\footnotetext{
39 Ibid.

$40 \mathrm{Ibid}$.

$41 \mathrm{Ibid}$.

$42 \mathrm{Ibid}$.

43 Ibid.
}

De esta manera Solari hace entender al público lector que lo que le faltaba a Sabogal era una muy buena influencia para perfeccionar sus obras, e introduce la presencia de Hernández, además que requería de un elemento importante y característica del Modernismo y es el conocerse a sí mismo, llegar a la introspección.

Solari también menciona el viaje que hará Sabogal después de cerrar la exposición que se encontraba en el Casino Español. Y hace notar el gran cambio en las telas que exhibió en este lugar como resultado de un proceso de desarrollo:

"Son tan admirables esos cuadros que ellos constituirían en cualquier ciudad un verdadero acontecimiento artístico. Sabogal conserva todo su vigor innato y ha aprendido ya á administrarlo y á darle curso dentro de proporciones armónicas. Ya no se ve en las telas de Sabogal un incontenible arrebato genial en los trazos invariablemente desdibujados y entre un conjunto de tonalidades valientes pero sin gracia ni distinción. Las telas que Sabogal que va a exhibir dentro de pocos días nos lo presenta transformado, elegantizado, armonioso. Las violencias de su temperamento castizo español, temperadas por la influencia académica de Daniel Hernández, han culminado en una felísima fusión de las artes español y francés; y los admirables desbordamientos del primero, encauzados por el sentido de la armonía que caracteriza al segundo, tienen en Sabogal un pintor que en cuanto llegue á Europa va á dar lustre á la mentalidad y á la producción artística del Perú." ${ }^{44}$

Solari comenta para esta muestra de 1921 , que Sabogal se ha encauzado gracias a la influencia de Daniel Hernández, y que así, las obras son armoniosas en el manejo de las proporciones, el uso de los colores y tonalidades que se han elegantizado, han mejorado en calidad y esto lo hace notar a través de sus artículos y de alguna manera influenciando al público que seguía la actualidad del movimiento artístico cultural para las fechas de las celebraciones del Centenario de la Independencia del Perú “(...) será,

44 Ibid. 
sin duda, la de mayor trascendencia entre todas las celebradas hasta la fecha (...)"45, y lo sustenta “(...) porque en Sabogal se reúnen toda la orientación nacionalista de Castillo, un vigor inmensamente superior al de Baca Flor y una elegante estilización que tiene felices reminiscencias de Daniel Hernández (...)" "46. Este artículo causó la reacción de José Sabogal. ${ }^{47}$

El segundo artículo también se refiere a la muestra que el artista realizó en el Casino Español. Es importante porque se llevó a cabo durante las celebraciones del primer Centenario de la Independencia del Perú, escribe:

“(...) Si elogios entusiastas merece este artista ya formado,(...) también los merece por la sinceridad de su técnica sobria y briosa. Su pincelada es amplia y atrevida, extensa, emotiva y segura. Ama Sabogal las tonalidades acentuadas fuertes; sus telas dan siempre la sensación de un arte masculino y recio en su factura, pero á veces - especialmente los lunados- obtiene la interpretación de visiones de una delicadeza exquisita. De todos los cuadros (...) donde Sabogal es más Sabogal, es (...) El Caporal Juan Pizarro"48.

Aquí podemos observar algunas de las características de la obra del pintor; cuando describe que su pincelada es amplia y atrevida, demuestra una de las técnicas reconocidas en lo que llamamos el estilo Indigenista que aún estaba formándose, y que no era conocido con esta denominación. Además, observa Solari en Sabogal una técnica de arte masculino, refiriéndose a que su factura es recia, al representar a sus personajes grotescamente pero que, sin embargo, también es delicada al representar los lunados, refiriéndose al trabajo de las sombras.

En la publicación de este artículo se ve, por primera vez, la imagen de un grabado de una

$45 \mathrm{Ibid}$.

46 Ibid.

47 Lo que escribió Solari sobre la obra de Sabogal, le valió al artista para elaborar una respuesta donde manifiesta no estar de acuerdo con respecto a la influencia que Daniel Hernández pudo tener en su obra.

48 Don Quijote, 1921b: 10

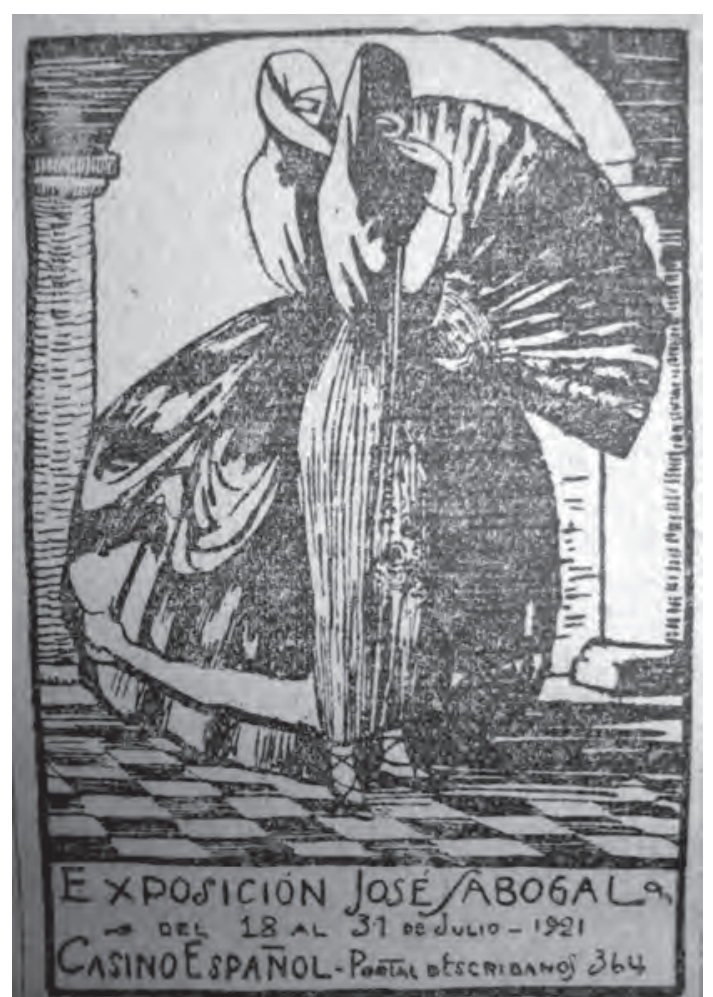

Figura 3: Don Quijote, Tapadas, grabado de José Sabogal. En El Comercio, 1921f: 10

obra de Sabogal denominada "Tapadas" (Figura 3) que estaba en la exposición, hecha de tal factura que era merecedora de ser publicada en el diario El Comercio.

En el tercer artículo Solari menciona la participación de Sabogal en la exposición en el salón del Palacio de Gobierno con motivo de las celebraciones del Centenario de la Batalla de Ayacucho,

"Para el citado salón de Palacio, Sabogal ha ejecutado ocho grandes telas de temas incaicos y coloniales (...) todo su original y vigoroso talento ha puesto Sabogal en esas telas de aspecto suntuario y de deliciosa decoración (...)"49.

Vemos que el artista, en las dos fechas correspondientes a las celebraciones de los Centenarios, participó con exposiciones que tuvieron

49 Don Quijote, 1924: 2 
una gran acogida tanto del público como de las autoridades del ambiente artístico y político e, incluso, motivó polémica. (Figura 4).

\section{Conclusiones}

1. El trabajo que realizó Carlos Solari Sánchez Concha es de crítica de arte a través del desarrollo de crónicas. Influenció al público y hasta a las autoridades, en el gusto por las obras de artistas que se encontraban en el lineamiento del modernismo, haciendo ver que era el movimiento que estaba de moda en la élite artístico cultural de Lima, refiriéndose al grupo de intelectuales, educados refinados y de buen gusto.

2. Sus publicaciones mencionan los lugares donde se llevaban a cabo las exposiciones como el Casino Español, la Fotografía Rembrandt, Club Italiano, Sociedad de Bellas Artes, Casa Roggero; por ello nos damos una idea de que estos espacios no eran exclusivos de exposiciones sino que compartían otras actividades (sociales y comerciales).

3. Deja ver que dependía de los críticos orientar a la alta sociedad para adquirir obras expuestas, situación que no es ajena hoy en día.

4. El crítico pertenece a una etapa de cambio y desarrollo en la pintura por lo que se encuentra vinculado a influencias a nivel mundial de los movimientos artísticos como el modernismo así como el surgimiento en el medio local del indigenismo, aunque éste último aún no se conocía con ese término hasta muchos años después. Carlos Solari está en el lineamiento del modernismo cuyas características son: reinterpretación subjetiva del tema, síntesis en la representación de las figuras y de la composición pictórica validada por Solari como lo "moderno" en cuanto a la tendencia pictórica del medio local limeño.

5. Como planteamiento Solari ofrece un

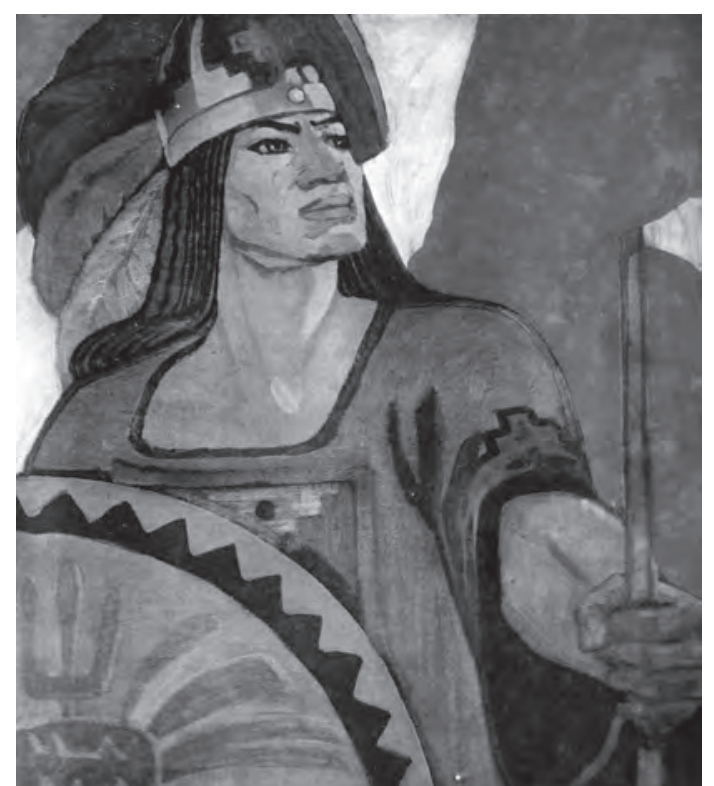

Figura 4: Sabogal, Perú. En Revista Mundial, 1923: carátula.

punto de vista particular, ver el ambiente artístico bajo preferencias y gustos modernistas, teniendo en cuenta que, en el medio local limeño, estaba surgiendo el gusto por los temas indígenas y criollos.

\section{BibliogRAFÍA}

El Comercio

1994 El siglo XX en el Perú a través de el Comercio, T. III. Lima, Empresa Editora El Comercio.

Paz-Soldán, Juan Pedro

1921 Diccionario Biográfico de peruanos contemporáneos. Lima, Librería e imprenta Gil.

Portocarrero Grados, Ricardo

1999 "Sensualidad y estética en los escritos de Juan Croniqueur (1914 - 1919)" En Mujeres y género en la Historia del Perú, Lima, CENDOC-MUJER (Centro de documentación sobre la mujer, Asociación Civil), pp. 373 - 393.

Robalino Sánchez, Karla

2009 La crítica de arte de Carlos Solari Sánchez Concha publica en el diario El Comercio desde1919 1924. Tesis para obtener el título profesional de Licenciada en Arte. 
Universidad Nacional Mayor de San Marcos. Facultad de Letras y Ciencias Humanas. Escuela Académico Profesional de Arte.

Schmutzler, Robert

1985 El Modernismo. Madrid, Alianza Editorial S.A.

Sembach, Klus-Jürgen

2007 Modernismo. Madrid. Taschen.

Swayne y Mendoza, G.

1940 Mis Antepasados. Genealogía de las familias Swayne, Mariátegui, Mendoza y Barreda. Lima, Talleres gráficos de la tipografía peruana S.A.

Varios autores

2009 Enciclopedia Universal. Madrid. Vol. 9, 11,17 y 30.

Venturi, Lionello

1949 Historia de la Crítica de Arte. Buenos Aires, Editorial Poseidón.

\section{HEMEROGRAFÍA}

Anónimo

1920a "Crónica. De arte". En El Comercio, Lima, enero 5, p. 1.

1920b "Notas de Arte", En El Comercio, Lima, enero 6, p. 3.

1932 "Notas Sociales". En El Comercio, Lima, abril 27, p. 12.

Cáceres, Esteban M.

1921 "Notas de arte/ La música y la Pintura/ Dedicado a la Sociedad de Bellas Artes de Lima”. En El Comercio, Lima, junio 11, p. 2

C.P.

1920 “La exposición Koek Koek". En: Revista Variedades, Lima, marzo 13, Año XVII, № $628, \mathrm{~s} / \mathrm{p}$.

Chioino, José

1921 "Visitando la exposición Sabogal". En El Comercio, Lima, julio 22, p. 5

Don Quijote

1919 "Notas de arte. Salón de humoristas". En El Comercio, Lima, junio12, p. 2

1920a "Notas de arte. Exposición Vinatea". En El Comercio, Lima, febrero 6, p. 4 1920b "Notas de arte. La exposición Koek Koek". En El Comercio, Lima, marzo 10, p. 1

1920c "Notas de arte". En El Comercio, Lima, abril 15, p. 3

1921a "Notas de arte. La próxima exposición Sabogal”. En El Comercio, Lima, julio 8, p. 1

1921b "Notas de arte. Exposición Sabogal". En El Comercio, Lima, 28 julio, p. 10

1921c "Notas de arte. La exposición EgurenLarrea”. En El Comercio, Lima, agosto 3, p. 2

1924 "Notas de arte. Exposición Tadolini. Unas telas de Castillo. Romántica Visita á la Escuela de Bellas Artes”. En El Comercio, Lima, diciembre 15, p. 2

D.Q.

1921a "Nota de arte. La exposición Masías". En El Comercio, Lima, abril 16. p. 2

$1921 b$ "Notas de arte. Exposición Challe". En El Comercio, Lima, abril 18, p. 4

1923 "Notas de arte. Una artista de verdad". En El Comercio, Lima, setiembre 27, p. 3

Jufebrand

1920 "Notas de arte. Un mensaje de Soiza Reilly/ Nuevo libro de la señora Larriva de Llona”. En El Comercio, Lima, marzo 1, p. 3

Paz Soldán, Juan Pedro

1920 "El pintor Stephen Koek Koek". En El Comercio, Lima, marzo 23, p. 1

Sabogal, José

1923 "Perú. Carátula de José Sabogal". En Revista Mundial, Lima, julio 27, № 167 Año IV, carátula.

Sánchez-Concha Barrios, Rafael

1999 "Historia y Genealogía de la familia Sánchez Concha". En Revista del Instituto Peruano de Investigaciones Genealógicas, Lima, № 22, p. 237-290

Solari, Carlos

1921 "Notas de arte. Una carta de José Sabogal próxima exposición de las obras del artista”. En El Comercio, Lima, julio 16, p. 2

Vinatea Reinoso, Jorge

1923 "El indio del cántaro/ Acuarela de Vinatea Reinoso". En Revista Mundial, Lima, agosto 3, № 168 , Año IV, carátula. 